Anuario del Instituto de Historia Argentina, vol. 17, n 2, e054, diciembre 2017.

ISSN 2314-257X

Universidad Nacional de La Plata.

Facultad de Humanidades y Ciencias de la Educación.

Centro de Historia Argentina y Americana

\title{
"Castigar los crímenes de la anterior administración". El juicio contra los miembros del Directorio y del Congreso en 1820
}

\author{
"To punish the crimes of the previous administration". The trial \\ against members of the Directorio and Congreso in 1820
}

\section{Irina Polastrelli}

Instituto de Estudios Críticos en Humanidades (IECH), Universidad Nacional de Rosario, CONICET, Argentina | iripolastrelli@gmail.com

\section{PALABRAS CLAVE}

Buenos Aires

Crisis de 1820

Justicia

Política

“Alta traición”

\section{KEYWORDS}

Buenos Aires

Crisis of 1820

Justice

Politics

"High treason"

\section{RESUMEN}

Este artículo analiza el proceso que el gobernador de Buenos Aires, Manuel de Sarratea, instruyó en 1820 contra los miembros del Directorio y del Congreso. El propósito es mostrar las dificultades de evaluar el desempeño de quienes habían ejercido el poder en un contexto en el que los nuevos principios que debían regular "la política" estaban en discusión. Se estudian el formato judicial, el delito imputado, los conflictos jurisdiccionales y las disputas entre las autoridades políticas involucradas. El juicio condensa los dilemas que caracterizaron a la coyuntura de 1820: cuestionamiento de autoridades y superposición de sujetos soberanos.

\section{ABSTRACT}

This article analyzes the trial executed by the governor of Buenos Aires, Manuel de Sarratea, againt the members of Directorio and Congreso in 1820. The purpose is to show the difficulties of evaluating the performance of those who had exercised power in a context in which the new principles that had to regulate "politics" were under discussion. It examines the judicial format, the imputed crime, the jurisdictional conflicts and the disputes between political authorities involved. The trial condenses the dilemmas that characterized the situation of 1820: questioning of authorities and superposition of sovereign subjects. 


\section{Introducción}

Pedro León Gallo, diputado del Congreso General Constituyente, hizo público su repudio frente a los "principales vicios" que invalidaban la "famosa causa criminal de alta traición” instruida por el gobernador de Buenos Aires, Manuel de Sarratea. Además de calificar como "un acto estrepitoso” el arresto de los "representantes de los pueblos" y de remarcar el "descaro é imprudencia” de las imputaciones realizadas en su contra, Gallo cuestionó enérgicamente el rol desempeñado por Sarratea en el juicio. "Sin delicadeza ni pudor”, el gobernador se había instituido "contra todo derecho en Juez" de los diputados, usurpando "una jurisdicción que por ningún título podía competerle” para "formar con aparatos imponentes” la "ruidosa causa” (Gallo, 1820). En el libelo del diputado, escrito a comienzos de mayo de 1820 luego de la renuncia de Sarratea y de la suspensión del proceso, se condensaban varias cuestiones: quién debía juzgar a los representantes, a partir de qué mecanismos, cómo debían marcarse los límites al accionar de la propia elite dirigente. En suma, lo que ponía en evidencia Gallo era cómo resolver la complicada tarea de definir el ejercicio de la justicia que, en este caso, implicaba precisar los mecanismos para enjuiciar a las autoridades en el proceso de tránsito del orden colonial al revolucionario. Los vínculos entre política y justicia desde la perspectiva aquí recortada ponen de relieve la pregunta acerca de cuáles debían ser dichos mecanismos y quién debía hacerse cargo de implementarlos.

El dilema de juzgar a gobernantes que habían cesado en sus funciones para determinar sus responsabilidades políticas se había presentado en otras oportunidades durante la primera década revolucionaria. $\underline{1}$ En 1813 la Asamblea General Constituyente residenció -en nombre de la “nación”- a quienes habían ejercido cargos gubernamentales desde la remoción del virrey en 1810, aunque su intención fue la de reprimir y castigar a la facción encabezada por Cornelio Saavedra (Polastrelli, 2013). En 1815, luego de la destitución del director supremo Carlos de Alvear y de la disolución de la Asamblea, una comisión designada por el Cabildo de Buenos Aires enjuició a miembros de los poderes ejecutivo y legislativo bajo la acusación del "delito de facción" (Ternavasio, 2007). La historiografía tradicional ha transitado largamente este tipo de procesos judiciales, tanto durante la colonia (cuando la residencia era parte regular de la administración) como en el período abierto con la revolución, siendo sus aportes fundamentales a la hora de reconstruirlos. 2 Obras como las de de Manuel Ibáñez Frocham (1938), Ricardo Mariluz Urquizo (1953), Luis Méndez Calzada (1960) y Ricardo Levene (1962), sin embargo, se centraron más en el estudio de textos normativos y de obras doctrinarias que en la lógica de funcionamiento efectivo de estas instituciones y de las prácticas encarnadas por diversos actores. La revisión de muchos de los problemas planteados por estos autores ha sido posible gracias a la fértil confluencia entre historia política, historia del derecho e historia de la justicia que tuvo lugar en los últimos años. La renovación de dichos campos -que se dio en simultáneo con la ocurrida en los estudios relativos a las revoluciones hispanoamericanas y los procesos de formación de los estados nacionales- resultó en lecturas innovadoras que enriquecieron la mirada jurídico-institucional de las fuentes judiciales para reflexionar sobre el ámbito de lo político. $\underline{3}$

Este artículo se inscribe en estas nuevas líneas interpretativas. A partir del análisis del proceso judicial que el gobernador de Buenos Aires, Manuel de Sarratea, pretendió instruir en 1820 contra los miembros del Directorio y del disuelto Congreso, se señalan algunas dificultades que se manifestaron al momento de definir delitos derivados de las “responsabilidades” en el ejercicio del 
poder en una coyuntura en la que "la política”, como actividad, se veía sometida a la discusión de los nuevos principios que debían regularla. Se estudian el formato judicial al que fueron sometidos los acusados, los conflictos jurisdiccionales que se originaron y las disputas suscitadas entre las autoridades políticas involucradas. Además, se presta particular atención a los conceptos y las ideas que guiaron la revisión de la conducta de los gobernantes desplazados y que se deducen de la acusación y de los alegatos de defensa.

\section{La caída del poder central y el juicio de 1820}

Luego de la sanción de la Constitución centralista en 1819, y del rechazo que suscitó en las provincias del Litoral, el poder central entró en una crisis infranqueable que culminó con su derrota militar a manos de las fuerzas federales de Estanislao López y Francisco Ramírez en Cepeda, a comienzos de febrero de 1820. La disolución del Congreso General Constituyente y la desaparición del Directorio provocaron un vacío de poder sin precedentes, conocido en la historiografía tradicional como la "anarquía del año 20”. Los vencedores presionaron al Cabildo de Buenos Aires para que asumiera la autoridad de la ciudad y su entorno rural y nombrase un nuevo gobierno, afín a sus intereses, para negociar la paz. Mediante un cabildo abierto, el 16 de febrero fueron elegidos los doce miembros por la ciudad que conformaron la Junta de Representantes de Buenos Aires. Como debían sumarse los representantes de la campaña, la Junta designó de manera provisoria a Manuel Sarratea como gobernador. Sarratea había hecho carrera con la revolución, pero no gozaba de prestigio por sus permanentes intrigas. Miembro del Triunvirato en 1811, al año siguiente lideró el ejército en la Banda Oriental. En 1814, enviado por el director Gervasio Posadas, realizó una misión diplomática en Madrid y Londres. A su regreso, fue ministro del Directorio de Juan Martín de Pueyrredón, pero renunció y se integró a la oposición federal porteña. Acusado de liderar una conspiración contra el gobierno en 1817, fue desterrado.

El 23 de febrero de 1820 Sarratea firmó el Tratado del Pilar con Ramírez y López. Además de poner fin a las hostilidades, el acuerdo determinó que el principio federal regiría la futura organización del país, que se concretaría en un congreso a reunirse en San Lorenzo. Pero también estipuló que los miembros del Directorio y del Congreso debían ser sometidos a un juicio público para justificar los “motivos poderosos” por los que los "Xefes del Exercito Federal” habían declarado la guerra a Buenos Aires. 4 Ramírez y López no detentaban la representación del resto del territorio, a diferencia de la Asamblea General Constituyente y el Cabildo de Buenos Aires que dispusieron los enjuiciamientos de 1813 y 1815. Pero el peso de sus liderazgos políticos y militares puso a los jefes federales de Entre Ríos y Santa Fe en una posición de superioridad, frente a la vapuleada Buenos Aires, para imponer el procesamiento. Una condición que de ser cumplida por Sarratea le garantizaba el apoyo de Ramírez y de López y, por lo tanto, el cargo de gobernador en una coyuntura en la que los caudillos del Litoral, las tendencias centralistas representadas por los directoriales desplazados y los grupos federalistas porteños pugnaban por hacerse con el poder político. La intención política que movilizó a Sarratea a iniciar el juicio, entonces, trascendía el mero deseo de "hacer justicia” frente a los abusos de la administración removida, y debe ser ponderada bajo estas circunstancias.

La Junta de Representantes ratificó el Tratado del Pilar, y ante la consulta de Sarratea sobre el modo 
de tramitar la causa, le sugirió que nombrara una comisión de una o más personas del "fuero común” e "imparciales”, dirigida por "un letrado de luces”. La comisión debía establecer una distinción en el procesamiento: las causas de los representantes de los "pueblos” que se mantenían "libres de la dominación enemiga" debían suspenderse para notificar a sus cabildos; mientras que los sumarios de los diputados de la ciudad de Buenos Aires o de aquellas ocupadas proseguirían hasta ser puestos en estado de sentencia. Por último, especificó que el congreso convocado por el Tratado del Pilar, debía nombrar al tribunal para dictar las sentencias definitivas (Anchorena, 1820a, pp. 3-4). La propuesta de la Junta de designar una comisión especial de justicia recuperaba una vieja práctica que, a pesar de su extendido rechazo público y formal, continuó siendo utilizada en momentos críticos. De hecho, los procesos judiciales ordenados por la Asamblea en 1813 y el Cabildo de Buenos Aires en 1815 fueron sustanciados mediante comisiones. Sin embargo, como señaló Magdalena Candioti (2015), esta práctica no constituía simplemente una herencia o un problema coyuntural, sino que evidenciaba la imposibilidad de prescindir de instancias de "juicio político” y, por ende, el carácter inconjurable de la confluencia entre lo político y lo jurídico. Por otro lado, la sugerencia de hacer partícipes a los cabildos del procesamiento de los diputados devela la persistencia de una cultura jurídica, anclada en la tradición hispánica, que reconocía atribuciones jurisdiccionales en los “pueblos”. Pero también el ánimo de la Junta de eludir el cumplimiento de la exigencia incómoda de enjuiciar a los directoriales, en un contexto en el que las disputas entre centralistas y confederacionistas en Buenos Aires se entrecruzaron con una profunda división facciosa.

La agitación política se exacerbó cuando el 6 de marzo de 1820 un movimiento liderado por el ex directoral Juan Ramón Balcarce, y apoyado por los sectores porteños descontentos con las imposiciones del Tratado, derrocó a Sarratea. La Junta de Representantes suspendió sus sesiones y una asamblea de vecinos nombró gobernador a Balcarce. Pero a los pocos días la presión ejercida por Ramírez repuso a Sarratea en su cargo (Herrero, 2010). Luego del episodio, Sarratea arrestó a los miembros del Directorio y del Congreso que permanecían en la ciudad $\underline{5}$ y retomó las gestiones del juicio, dando a conocer a un bando en el que se subrayaron dos tópicos legitimadores del procedimiento escogido: el "imperio de las leyes” y el "juicio público”. La retórica del imperio de la ley asumió una preeminencia legitimadora central luego de la revolución, convirtiéndose en un objeto de disputa entre las facciones que pretendieron atribuirse su custodia (Candioti, 2015). Sarratea remarcó en el comunicado que, aunque "la magnitud y publicidad” de los crímenes autorizaban el castigo directo, el proceso judicial era necesario para infundir "seguridad y confianza en el imperio de las leyes”. Asimismo, el compromiso de divulgar la causa obedecía al propósito de diferenciarla de las sustanciadas en 1813 y 1815, de las que sólo se difundieron las sentencias en El Redactor de la Asamblea y en La Gaceta, respectivamente (Proceso..., 1820, pp. 3-4).

El bando ofició como introducción al auto cabeza del proceso, en el que Sarratea autorizó la utilización de las actas secretas del Congreso como testimonios, designó a Juan Bautista Villegas fiscal acusador y anunció que su gobierno sólo sustanciaría las causas, ya que por la gravedad del asunto se debía dejar en manos de "los pueblos” la resolución definitiva. Para pronunciar las sentencias se invitaría a "las provincias interesadas” a que nombrasen cada una un juez, que debía presentarse en Buenos Aires. De no acordar con la modalidad, los diputados podrían ser remitidos con sus causas concluidas para que cada “pueblo” lo juzgase por sí mismo. Por último, el gobierno 
de Buenos Aires se comprometía a tomar las medidas necesarias para facilitar la reunión del tribunal que debía fallar en última instancia (Proceso..., pp.5-6).

Se ha discutido si la "absorción jurisdiccional” realizada por Sarratea al designar al fiscal, ofrecer las opciones para que cada provincia decidiese cómo juzgar a sus diputados y, finalmente, erigirse él mismo en juez, contaba con algún sustento legal. Joaquín Pérez (1950) sostuvo que el accionar del gobernador se había ajustado a derecho puesto que se amparaba en el Tratado del Pilar, aprobado por las autoridades de Buenos Aires. Para Luis Méndez Calzada (1960), Sarratea se había valido de las amplias facultades con las que la Junta de Representantes lo había revestido al nombrarlo como gobernador para ejercer la "potestad judicial”. Pero aún con la aquiescencia de la Junta, este reforzamiento del ejecutivo que lo convertía en "dispensador de justicia” expresaba el debilitamiento del poder judicial, porque Sarratea había prescindido para la formación del sumario, la disposición de arrestos y la producción de pruebas de la Cámara de Apelaciones, el órgano judicial de la provincia de Buenos Aires. Este enfoque de las facultades extraordinarias como anomalía constitucional obvió, según José C. Chiaramonte (2010), la atención sobre su concordancia con la "constitución antigua”. Ceñidas a antiguas pautas del derecho político, y difundidas en la época para afrontar crisis políticas, no eran usurpadas por el gobernador: la institución representativa de la soberanía popular se desprendía temporalmente de ciertas facultades con el argumento de que la gravedad de la coyuntura dificultaba su tramitación mediante los procedimientos de la división de poderes (Tau Anzoátegui, 1961; Agüero, 2016). Un principio que, por otro lado, recién comenzaba a ser debatido en el marco de un orden jurisdiccional que no reconocía la distinción clara entre funciones ejecutivas y judiciales (Ternavasio, 2007). En esta lógica jurídica tradicional se amparó Sarratea cuando fue acusado por la Junta y los diputados procesados de arrogarse competencias que no le correspondían a su título de gobernador.

\section{¿Nación o pueblos? Una jurisdicción en disputa}

En el cuaderno publicado de la causa se conservan las respuestas de los cabildos de Tucumán y de Córdoba, que también había recibido misiva de su diputado Benito Lascano pidiendo "someter a juicio su conducta representativa”. El Cabildo cordobés acordó por mayoría de votos reclamar la persona del diputado para su juzgamiento en dicha "Provincia”, por lo que a fines de abril Sarratea le ordenó a Lascano salir de la ciudad en el plazo de tres días con el sumario impreso (Proceso..., 1820, pp. 58). En el desenlace de este caso se observa una predominancia de la lógica representativa que ubicaba la soberanía en los pueblos. La concepción del carácter soberano de los pueblos estaba unida a la práctica del mandato imperativo: los diputados eran considerados apoderados de los mismos (Chiaramonte, 1999; Manin, 2006; Palti, 2007). Por lo tanto, su desempeño en el Congreso debía ser evaluado por el sujeto soberano que les había conferido sus facultades. Sin embargo, la solicitud presentada por otro diputado no tuvo una resolución expeditiva y provocó la renuncia del fiscal Villegas debido al choque que mantuvo con el asesor de gobierno Pedro José Agrelo. $\underline{6}$

El altercado entre Villegas y Agrelo reveló una fuerte disputa en torno a la potestad del gobernador Sarratea para enjuiciar a los acusados y también sobre los sujetos de imputación soberana ante los cuales los gobernantes “debían rendir cuentas” en calidad de comisionados. Chiaramonte (1997) destacó que la representación era uno de los elementos que definía la posesión o la carencia de 
calidad soberana de los pueblos y que por eso fue central en los enfrentamientos de la primera mitad del siglo XIX. En este sentido, las reuniones constituyentes fueron escenarios de encarnizadas disputas respecto de dicha cuestión. Al comienzo del Congreso de Tucumán, como consecuencia del reflujo político caracterizado por la recuperación del poder por parte del Cabildo porteño luego de la crisis de 1815, se había adoptado la figura del apoderado (Chiaramonte, 1999). Sin embargo, la discusión abierta con el pedido del diputado catamarqueño expuso la tensión ocasionada por la convivencia de distintas soberanías que reclamaban la atribución de juzgar a sus representantes.

El 23 de marzo de 1820 Manuel Antonio Acevedo, diputado de Catamarca, solicitó al fiscal que su causa fuese trasladada por problemas de salud a su provincia. Villegas le concedió el permiso porque el juicio padecía "notables vicios”:

siendo los acusados unas personas públicas que solo deban responder ante su comitente, todo paso que no se apoye en el consentimiento expreso de la nacion á la cual representan, lleva consigo los vicios de nulidad, y ataca directamente los sagrados derechos de los pueblos unidos. Bajo este principio de eterna justicia ¿como podrá el Gobierno de una Provincia arrogarse esclusivamente el privilegio de sustanciar el juicio? ¿Cómo ejercer un acto de jurisdicción de que se carece, y prevenir la opinión pública antes que el juez legítimo pronuncie su sentencia? (Proceso..., 1820, pp. 5253).

La cita ilustra la imprecisión respecto de los términos que circulaban para denominar a las entidades soberanas. Los diversos significados asignados al conflictivo binomio integrado por las nociones de nación y pueblo/pueblos y las tensiones con el concepto de soberanía han sido explorados en detalle (Souto y Wassermann, 2008; Goldman y Di Meglio, 2008). La asociación entre “nación” y "pueblos" (o provincias) da cuenta de que los últimos eran portadores de soberanía y sujetos de derecho para actuar de manera legítima, en este caso, enjuiciando a sus representantes (Souto y Wasserman, 2008). La noción plural de nación subyace en el planteo de Villegas, que cuestionaba la legitimidad del gobierno de Buenos Aires para enjuiciar a los diputados puesto que, al desempeñarse como representantes de su "nación” en el Congreso, la evaluación de sus funciones era jurisdicción de su respectivo "comitente”. Por otro lado, el hecho de que Sarratea actuase sin la aprobación de los “jueces legítimos” -es decir, de los sujetos soberanos cuya representación delegada había sido agraviada- minaba también su propia legitimidad como fiscal, a pesar de la intención del gobierno de proceder “según la ley” (Proceso..., 1820, pp. 52-53).

El dictamen de Villegas fue reprobado por Agrelo, que reiteró que en el auto cabeza del proceso se había reservado a "los pueblos absolutamente el juicio último de la causa”, pero que al gobierno de Buenos Aires le tocaba sustanciarla. Afirmó que a "los pueblos” les correspondía optar entre el envío de sus representantes para "juzgarlos separadamente” y la reunión en un "Tribunal Supremo General dé la Nación” para "residenciarlos á todos”, por lo que otorgar el permiso al diputado Acevedo sin tener conocimiento de dicha resolución faltaba al respeto que merecían "los derechos de los Pueblos". Agrelo concluyó que el solicitante debía esperar "hasta la decision de su comitente" (Proceso..., pp.53-56). Luego de dictaminar sobre el caso de Acevedo, el asesor esclareció el asunto de la representación política de los diputados del Congreso: 
Pero aun cuando el comitente fuese el Pueblo determinado que los nombro, la responsabilidad que cargan al admitir la diputación es in solidum y mancomunada á toda la Nación, y á cada Pueblo y Provincia en particular, como que no son solos los derechos, y los bienes y males particulares de un Pueblo ó Provincia, sobre los que vienen á tratar y decidir, sino sobre todos los de la Nación: por consiguiente la acción contra ellos es de la misma naturaleza, y no solo toda la Nación junta, pero cada Provincia, ó Pueblo también en particular puede pedirles cuenta de su versación, y el desempeño de sus deberes (Proceso..., pp. 53-56).

El fragmento pone en evidencia cómo el problema de definir a qué entidad imputar la soberanía se traslucía en la discrepancia en torno del carácter representativo de los congresales y, en virtud de esto, en la cuestión concreta de a qué autoridad correspondía juzgarlos. Agrelo defendió la posición de que los diputados eran responsables ante la nación por sus actos a partir de tres premisas: los diputados habían adoptado esa denominación en el Congreso, sus pagas se habían realizado de fondos "nacionales" y los temas tratados en las sesiones concernían a la nación toda y no a los pueblos o las provincias en particular. Las provincias y los pueblos que habían enviado a sus representantes al Congreso eran soberanos y, en consecuencia, habían decidido constituir una nación al trasladar su soberanía al nuevo sujeto de imputación soberana (Souto, 2016). Es decir, admitía que los congresales habían sido electos como comisionados por los pueblos, pero eso no significaba que la nación quedara relegada como su comitente porque su representación se encontraba subsumida en ese nombramiento. Para Agrelo, las representaciones no eran excluyentes entre sí, aunque le otorgaba preeminencia a la nacional por sobre la de los Pueblos, retomando la idea contractualista de una nación basada en cuerpos colectivos e impulsada por el consentimiento, en contraposición a la experiencia constitucional fracasada en 1819 concebida en los términos de una soberanía indivisible (Botana, 2016).

Dilucidar si la prerrogativa de evaluar la actuación de los diputados correspondía a la nación o a los pueblos y las provincias era crucial para el momento en que se desarrollaba la causa, ya que implicaba precisar qué autoridad haría uso de esa atribución soberana, diseñando al mismo tiempo una particular relación entre aquella y el resto de los cuerpos territoriales sobre los que pretendía imponer su jurisdicción. En ocasión de los procesos judiciales de 1813 y 1815, la Asamblea General Constituyente y el Cabildo de Buenos Aires evaluaron judicialmente el desempeño de quienes habían ejercicio cargos en los gobiernos precedentes. Aunque sostenidos por distintas lógicas respecto de la asunción de la soberanía, ninguno fue impugnado en ese rol puesto que detentaban la representación incuestionable de -prácticamente- todo el territorio rioplatense. Es decir, los juicios efectuados no fueron objetados porque las autoridades que los habían originado no fueron puestas en entredicho, como sí ocurrió en 1820.

\section{Dirimiendo fuerzas. El gobernador versus la Junta de Representantes}

El 27 de abril de 1820 se realizaron elecciones para designar una nueva Sala de Representantes, que debía nombrar al diputado de Buenos Aires para el congreso de San Lorenzo. Sarratea vetó la elección de Tomás Manuel de Anchorena, Juan José Paso, Vicente López y Juan Pedro Aguirre con el argumento de que estaban procesados por integrar la administración anterior y ordenó su arresto. Aguirre estaba imputado por haber participado en la fuga de Pueyrredón y Gregorio Tagle, López 
por ejercer como secretario durante el gobierno de Pueyrredón y Paso y Anchorena por sus funciones como diputados en el Congreso. Anchorena hizo pública una excusación para defenderse de la acusación de Sarratea, iniciando un jugoso intercambio de réplicas con el gobernador que aporta información complementaria. Anchorena formaba parte de una elite urbana que había conseguido salvar su patrimonio durante la revolución, más devota a sus propios intereses que a una tradición político-ideológica y cuyo peso sería evidente en la conformación de las sucesivas Juntas de Representantes (Halperin Donghi, 2005). En el debate sobre las formas de gobierno en el Congreso, es conocida su intervención abogando por el establecimiento de una "federación de provincias”, en oposición a la postura monárquica. Sin embargo, el régimen monárquico constitucional no era lo que motivaba su impugnación, sino la pretensión de que el rey coronado fuese un descendiente de los incas (Segreti, 1994; Souto, 2016).

En su excusación Anchorena cuestionó, en nombre del principio de división de poderes, el uso arbitrario de facultades por parte de Sarratea, puesto que no se correspondían con su cargo de gobernador:

No sé de donde nos ha salido un Gobernador de Provincia que habiendo jurado desempeñar fiel y legalmente su empleo conforme á las leyes que rigen en el pais, y no reuniendo en sí otra autoridad ni funciones que las que corresponden á su título, hace de Gobernador, de magistrado ordinario de justicia, de juez de residencia, de legislador, atropella todas las formas judiciales, pone en prisiones á los ciudadanos y los detiene en ellas largo tiempo, (...) en una palabra, se presenta con mas autoridad que el mismo Ser Supremo (Anchorena, 1820a, p. 1).

Ante el conflicto, la Sala de Representantes resolvió a comienzos de mayo de 1820 incorporar a los representantes vetados y ofició a Sarratea para que los liberase y le remitiera los procesos en curso. Aclaró también que su contestación a la consulta realizada por el gobernador al momento de iniciar las causas se había centrado en dos cuestiones relativas al Tratado del Pilar. La primera ponía en debate la pertinencia del procesamiento de los representantes al establecer una distinción entre los integrantes de la gestión desplazada. Para la Junta el tratado exigía "castigar los crímenes de la anterior administración”, enunciado que exceptuaba a los diputados del Congreso porque al formar parte de "un cuerpo legislativo" nunca habían ejercido "ramo alguno" en ella. El recurso al principio de división de poderes volvía a ser utilizado para cuestionar el proceder de Sarratea, pero esta vez para diferenciar funciones y deslindar responsabilidades dentro de un gobierno. La diferenciación entre "poder ejecutivo" -identificado con la “administración”- y "poder legislativo" -equiparado al Congreso, del cual se obviaba su labor constituyente- resultaba una premisa eficaz para impugnar las causas contra Anchorena, Aguirre, Paso y López, y el veto que les impedía incorporarse a la Junta. La segunda cuestión refería al rol que los gobernadores de Entre Ríos y Santa Fe habían jugado como promotores del enjuiciamiento de los directoriales. Aunque en la primera contestación no había observación alguna sobre el tema, esta vez la Junta objetó la validez de origen del proceso judicial al sostener que la obligación de expresar los motivos por los cuales se había declarado la guerra a Buenos Aires era de Ramírez y López (Anchorena, 1820a, p. 4).

Sarratea entregó a la Junta los procesos inconclusos y un alegato para justificarse ante el cuestionamiento del uso de atribuciones judiciales: 
Asi fue que sobreviniendo la revolución de 6 de Marzo, y variadas las circunstancias: complicados mas los intereses, y dificultada cada vez mas esta operación, resolví formarla yo mismo, justificar los hechos, y ponerla al fin en la decisión de un tribunal supremo judicial de la nación, como resulta del auto cabeza de proceso, dejando siempre á los pueblos la opinión de pedir sus diputados (...) Mas lo cierto es que la jurisdicción de un magistrado público no depende de opiniones sino de la ley, y de la voluntad bien expresa de las provincias federadas (Oficio..., 1820, pp. 3-4).

El gobernador afirmó que la prerrogativa para ejercer su jurisdicción en el juicio había sido aprobada por la Junta de Representantes y el Cabildo porque ambas corporaciones habían autorizado no sólo la rúbrica del Tratado del Pilar (que le garantizaba la legitimidad proveniente del beneplácito de los jefes federales), sino también las primeras gestiones judiciales realizadas, como el nombramiento del fiscal y el pedido sobre los diputados presos elevado por el cuerpo capitular. En cuanto a la reconvención de no haber nombrado un tribunal, Sarratea argumentó que la inestable situación de la provincia (agravada por el levantamiento de Balcarce a comienzos de marzo) había justificado su intervención como juez en la causa, ya que lo fundamental era la resolución expeditiva del asunto. Historiadores del derecho han señalado que la intervención del "poder ejecutivo" en las funciones del "poder judicial” (una de las críticas de los detractores de Sarratea) constituyó una de las “anomalías” que se repitieron durante todo el proceso revolucionario. Tal caracterización, que presupone un modelo de organización política fundado en el moderno principio de división de poderes que habría sido sistemáticamente violado, no se ajusta a la coyuntura analizada. Como ya se ha señalado, más que un avance sobre los otros dos poderes, el proceder de Sarratea parecía formar parte de una práctica frecuente que consistía en el aumento de las facultades ordinarias del gobernador ante situaciones de excepción, dado que las funciones transferidas a la Sala de Representantes no la conformaron plenamente en un poder legislativo, y que la justicia no se integró como poder independiente hasta mucho después. En relación a esto, Oreste C. Cansanello (2003) sostiene además que Sarratea sustentó sus facultades para juzgar en una jurisprudencia que hundía sus raíces en la colonia y que aún no había sido modificada: las atribuciones del cargo de gobernador continuaban enmarcándose en las cuatro causas (hacienda, justicia, guerra y gobierno) que recayeron en la figura del Gobernador Intendente creada con la Real Ordenanza de 1783.

Los embates de la Junta debilitaron la posición de Sarratea, que se resintió por la pérdida de apoyo de los jefes federales. A comienzos de mayo, presentó su renuncia y se dio a la fuga. La Junta de Representantes resolvió, a pedido del nuevo gobernador Ildefonso Ramos Mejía, que los detenidos fuesen puestos en libertad, aclarando que los diputados de Buenos Aires y de las ocupadas por el enemigo debían permanecer dentro de la provincia, mientras que la situación del resto de los diputados sería informada a "las Provincias libres" (Levantamiento..., 1879, p. 551). La causa iniciada por Sarratea como consecuencia del Tratado del Pilar quedó en suspenso. Días más tarde, la Junta nombró una "comisión de residencia” con el objetivo de “descubrir y castigar competentem.te" a quienes habían tomado parte "en los ultimos tiempos de la admnistrac.n de D. Juan Martin Pueyrredon, D. Jose Rondeau y D.n Man.l Sarratea”. $\underline{7}$ Sin embargo, el nuevo proceso judicial también enfrentó dificultades para su concreción. 


\section{El delito de “alta traición”}

El principal cargo imputado contra los procesados fue el delito de "alta traición”. En el bando de Sarratea la administración depuesta era caracterizada como una "tiranía”, puesto que había atentado contra "la vida, el honor, y la seguridad" de los “ciudadanos" y procurado "inutilizar la sangre derramada en diez años”, con el propósito de conducir al “estado” a una situación de "impotencia y degradación” para imponer "los tratados secretos" firmados "con cortes extranjeras”, instalar "un príncipe de la casa de Borbon” y renegar de "la independencia y libertad” proclamadas (Proceso..., 1820, pp. 5-6).

La crisis de 1820, con la disolución del gobierno central y el afianzamiento de las provincias autónomas, marcó el abandono definitivo de los proyectos monárquicos y la progresiva adhesión en torno a la república como solución plausible para la indefinición que dominaba el sistema político. Hasta entonces, la temprana adopción de un sistema representativo como modo de gestionar el poder no había implicado una identificación plena con la república, y la monarquía constitucional constituía una opción valorada por muchos para hacer frente a la incertidumbre reinante respecto de la forma de gobierno que las Provincias Unidas adoptarían luego de declararse la independencia en 1816. La vaguedad de los diversos estatutos y reglamentos -y en especial la de la Constitución de 1819- habilitó una ardua disputa en torno a las alternativas barajadas (Di Meglio, 2008). Las sesiones del Congreso y también la prensa periódica fueron escenarios de debate de las distintas posiciones respecto a las combinaciones que podían asumir las formas republicanas o monárquicoconstitucionales frente a los modos de distribución del poder a nivel territorial, es decir, proyectos centralistas o de unidad versus proyectos federales o confederales (Ternavasio, 2009; Gallo, 2016; Souto, 2016).

Aunque la acusación incluyó la misión diplomática realizada por Valentín Gómez en Francia para concertar la coronación del Príncipe de Luca, se centró fundamentalmente en las negociaciones que el Congreso General Constituyente había entablado con la Corte del Brasil. La impugnación al proyecto era doble: se cuestionaba la coronación de un monarca y también que éste estuviese vinculado a la Corte portuguesa, mirada con aversión desde la época colonial por sus intenciones expansionistas sobre el Río de la Plata (Ternavasio, 2015). Para el momento del procesamiento, la antipatía había trocado en hostilidad abierta como consecuencia del avance de las tropas lusobrasileñas sobre la Banda Oriental en 1816 y la toma de Montevideo en 1817. El avance además había sido consentido por el Directorio que, en su disputa con José Gervasio Artigas, líder de la Liga de los Pueblos Libres, había adoptado la pasividad como estrategia durante la confrontación. Como señaló Halperin Donghi (2005), las pretensiones monárquicas y la tibieza demostrada por el régimen directorial frente a la política expansionista de la Corte luso-brasileña, dieron forma al argumento de que la ideología revolucionaria había sido traicionada por la administración previa. El argumento resultó exitoso, puesto que logró coligar a los vencedores de Cepeda y a la oposición en la capital bajo la premisa de que la reivindicación de la ideología revolucionaria debía plasmarse en la búsqueda de un nuevo orden republicano y federal. Una cuestión que había sido planteada en el Tratado del Pilar, pero que con el inicio del proceso judicial adoptó una forma más acabada.

La causa no superó las instancias preliminares y los imputados no fueron interrogados por el fiscal, pero el contenido de la acusación puede ser ampliado a partir del intercambio de opiniones que mantuvieron Sarratea y Anchorena. Frente a los cargos de pretender instaurar una monarquía, 
Anchorena apuntó contra las misiones diplomáticas de Sarratea en Madrid y Londres, durante el Directorio de Posadas, para coronar como rey del Río de la Plata a un integrante de la familia de Borbón, Francisco de Paula (Halperin Donghi, 2010; Gallo, 2016). Si Sarratea no había sido considerado "delincuente" al firmar un tratado cuando las "provincias se hallaban divididas y sin representación” para gestionar dicha coronación, tampoco podía reputarse como tal al Congreso. Anchorena señaló la "menor" representatividad que había tenido Sarratea como enviado del Directorio, en contraposición al aval con el que habían contado los emisarios del Congreso, integrado por diputados representantes de buena parte de los territorios del Río de la Plata. Examinó también los dos planes monárquicos para justificar que entre "coronar un infante del Brasil, o de España”, era preferible el primero. Aunque reconocía que la monarquía había sido rechazada en las instrucciones de muchos de los diputados, la decisión de desatenderlas estaba justificaba porque esos "pasos políticos” habían sido dados para asegurar la independencia (Anchorena, 1820b, p. 8). Lejos de “merecer la nota de traidor”, el Congreso se convertía en "digno de la gratitud de los pueblos”. Las negociaciones en la Corte de Río de Janeiro habían tenido un objetivo esencial:

\begin{abstract}
¿No advierte V. que el gobierno Lusitano, habiendo trasladado su córte al Brasil, y radicandola en el Janeiro, ha pasado á ser de una potencia europea una potencia americana (...)? ¿Que la coronación de un infante seria un modo de ligar los intereses de la córte del Brasil con la de estas provincias, y aumentar en uno y otro estado el peso de su poder contra las aspiraciones del viejo mundo? ¿Que por consiguiente, sujetando al príncipe á una constitución liberal, no solo se salvaba la libertad é independencia del estado conforme á los votos de los pueblos, sino que, (...), dábamos mas respetabilidad y crédito á nuestra nación, poniéndola también a cubierto de los peligros de una vecindad absolutamente extrangera, y de cualquiera otra pretensión particular? (Anchorena, 1820b, p. 8).
\end{abstract}

Anchorena postuló la defensa del sistema monárquico constitucional, pero también la alternativa de “americanizar” la monarquía valiéndose del linaje dinástico de los Braganza emparentado con los Borbones. La sanción de la constitución permitía además ponerse a cubierto, ya que la propuesta monárquica quedaría reglamentada, sentando las bases de la organización política de los territorios rioplatenses y garantizando la independencia alcanzada respecto de la Corona española, pero también de la portuguesa, dejando de esta manera en claro -y por escrito- los límites de dicha vinculación. La constitución jugaba a dos puntas: hacia adentro de un territorio disputado obraría como emblema de un orden basado en la integración (y representado en la figura de un poder ejecutivo que con mínimas modificaciones podía ser encarnado por un monarca); hacia afuera, mirando el orden internacional nacido del Congreso de Viena, pretendía ser un instrumento de negociación y de inserción en el mundo de un territorio que había clausurado el ciclo revolucionario (Botana, 2016). La monarquía, con su constitucionalización y su americanización, tenía entonces una triple valía para Anchorena: acabaría con la indefinición del sistema político al instituir un nuevo orden que fuese reconocido en el concierto de naciones, y frenaría las eternas apetencias portuguesas de anexar el Río de la Plata a sus dominios. 


\section{Conclusiones}

Con la declaración de independencia en 1816, las Provincias Unidas habían resuelto su estatus jurídico-político al instituirse en un nuevo cuerpo soberano, la nación. Pero quedaba por resolver otra cuestión urgente: la sanción de una constitución para que la nación asumiera una forma política (Verdo, 2016). Sin embargo, la constitucionalización de esa nación se vería frustrada. El formato constituyente de 1819 fue impugnado por su carácter centralista, pero también por su orientación monárquica apenas disimulada (Halperin Donghi, 2005). Los proyectos monárquicos del Directorio y del Congreso fueron usados por Sarratea para dar forma al delito de alta traición y realizar la imputación exigida en el Tratado del Pilar (o, al menos, exhibir públicamente la pretensión de formalizar los cargos). La contraposición entre monarquía y república adquirió suma importancia como núcleo de la acusación, puesto que da cuenta del debate sobre la forma de gobierno que tuvo lugar durante el período constituyente de 1816-1819 y, en este sentido, contrasta con los delitos endilgados en las experiencias previas de enjuiciamiento de autoridades relevadas. En 1813 los saavedristas fueron procesados por atentar contra la supervivencia de la revolución al entablar relaciones con enemigos, trastornar "el orden y la tranquilidad pública” e incitar el "espíritu de división” mediante las facciones y los partidos (Polastrelli, 2013), mientras que en 1815 a los alvearistas se les atribuyó el “delito de facción”, en el que convergían numerosas infracciones al régimen representativo y al principio de división de poderes, entre ellas, la manipulación de las elecciones, la subordinación del poder legislativo al ejecutivo y la suspensión del decreto de seguridad individual (Ternavasio, 2007). Las acusaciones realizadas en 1813, 1815 y 1820, evidencian pues los desafíos que atravesó el proceso revolucionario en cada una de esas coyunturas (Polastrelli, 2017).

El proceso judicial de 1820 exhibe además cuán problemático resultaba enjuiciar a quienes habían detentado el poder en un orden cuya definición era motivo de encendidas disputas. Los diversos ensayos de organización política, el frustrado intento de dictar una constitución, la dificultosa puesta en funcionamiento del principio de división de poderes, pero fundamentalmente los conflictos para definir al sujeto de imputación soberana, tuvieron su correlato al momento de precisar la autoridad que debía conducir la "rendición de cuentas” de los gobernantes. En 1813 y 1815, los juicios habían sido dispuestos por la Asamblea General Constituyente y el Cabildo de Buenos Aires, ya que eran las autoridades que se habían arrogado la representación de las entidades soberanas que emergieron en dichas coyunturas. Pero en 1820 la incertidumbre respecto de qué autoridad debía atribuirse dicha facultad -y en nombre de quién- se tradujo en la incapacidad para sustanciar el juicio.

La imposible reconstitución de la autoridad central, y el inicio del proceso de surgimiento de los estados provinciales autónomos, se reflejaron en la particular dinámica de la causa judicial. Al dilema jurisdiccional, surgido como consecuencia de la convivencia de nación y pueblos o provincias como sujetos soberanos (derivado en la tensión entre las autoridades de Buenos Aires y del resto de los territorios), se sumó el enfrentamiento al interior de la propia provincia de Buenos Aires entre el gobernador y la Junta de Representantes. Mientras Sarratea lidiaba por conservar su frágil posición en una situación inédita de disputas exacerbadas, la Junta lograría consolidarse como un elemento ineludible en el nuevo equilibrio político. De junta electoral encargada de designar al gobernador, se fue convirtiendo en un cuerpo con capacidad para instituir -e imponer- los 
principios rectores del nuevo ordenamiento provincial (Halperin Donghi, 2010). El rol de la Junta de Representantes durante el fallido proceso, al cuestionar primero el proceder judicial del gobernador Sarratea (quien se justificó acudiendo a la lógica jurídica tradicional del aumento de facultades del ejecutivo durante emergencias políticas), y al objetar después la imposición de los jefes federales de someter a juicio a los directoriales caídos en desgracia, es indicativo de que la prueba de fuerza entre los diversos actores enfrentados comenzaba a resolverse a su favor.

La causa contra los "reos de alta traición", con sus continuas interrupciones y su posterior suspensión, condensa gran parte de los dilemas que caracterizaron al convulsionado año de 1820: cuestionamiento de autoridades y superposición de sujetos soberanos, en un contexto de provisionalidad permanente.

\section{Notas}

1 Historiadores del derecho españoles abordaron el tema de la responsabilidad política y judicial especialmente durante el primer constitucionalismo. Marta Lorente y José Portillo Valdés (2012) señalaron que la respuesta institucional al problema de quién juzgaría a los gobernantes luego de 1808 -cuando el rey impartía justicia pero no podía ser juzgado- fue la "resurrección” de la residencia. Desde otra perspectiva, Pierre Rosanvallon (2007) analizó la imbricación de las nociones de responsabilidad penal y política a partir de los procedimientos del impeachment inglés y del recall norteamericano.

$\underline{2}$ La denominación de estos procedimientos luego de la revolución en el Río de la Plata presenta ya una complicación, puesto que no se correspondieron con las residencias coloniales, pero tampoco con el moderno juicio político, establecido en la Constitución de 1853.

$\underline{3}$ Sobre los nuevos abordajes de la historia de la justicia, la historia crítica del derecho y la historia política, remitimos a Barriera y Tío Vallejo, 2012; Candioti y Tio Vallejo, 2012 y Goldman y Wasserman, 2016.

4 Pacto celebrado en la Capilla del Pilar entre los Gobernadores de Buenos Aires, Santa Fe y Entre Ríos (Ravignani, 1937, Tomo VII, $2^{\circ}$ parte, p. 131).

$\underline{5}$ En un parte enviado por Domingo French a Sarratea el 13 de marzo se mencionan los presos en el Cuartel de Cuna: Juan José Paso, José Teodoro Bustamante, Esteban Gazcón, Benito Lascano, Manuel Antonio Acevedo, Pedro Gallo, José Andrés Pacheco, el Deán Funes, Luis Chorroarín, Pedro Medrano, Vicente Anastasio de Echevarría y el canónigo Santiago Figueredo (Pérez, 1950, pp. 87-88).

6 Agrelo era también auditor general de guerra. En 1812 integró la comisión que juzgó la conjuración de Alzaga, fue diputado en la Asamblea del año XIII y participó de la comisión de Residencia; en 1815 fue desterrado por la Comisión Civil de Justicia y, en 1817, expatriado por el director Pueyrredón acusado de conspiración. Villegas se desempeñaba como asesor del defensor de pobres, y contaba con una rica trayectoria en cargos burocráticos y judiciales desde la colonia.

Z Archivo General de la Nación, sala X, 03-09-10. Gob. Nac. 1820. Mayo-Diciembre. 


\section{Fuentes publicadas}

Anchorena, T. M. (1820a). Excusacion de D. Tomas Manuel de Anchorena del empleo de Representante de la Provincia para el que le nombró el pueblo. Buenos Aires: Imprenta de Alvarez. Recuperado de: https://archive.org/details/excusaciondedtom00buen, pp. 3-4

Anchorena, T. M. (1820b) Satisfaccion que da al público D. Tomas Manuel de Anchorena sobre las falsas imputaciones que le hace D. Manuel de Sarratéa. Buenos Aires: Imprenta de la Independencia. Recuperado de: https://archive.org/details/satisfaccionqued00anch, p 8.

Gallo, P. L. (1820). Breves indicaciones sobré los principales vicios, é ilegalidades monstruosas de la famosa causa criminal de alta traición, formada contra el Congreso General Constituyente por el Gobernador Provisional de Buenos-Ayres D.Manuel de Sarratéa. Buenos Aires: Imprenta de Alvarez. Recuperado de: https://archive.org/details/brevesindicacion00gall

Levantamiento del arresto impuesto á los miembros del estinguido Congreso (1879). Registro Oficial de la República Argentina, Tomo I, p. 551. Buenos Aires: La República.

Oficio de la honorable junta de representantes al S. gobernador de la provincia; y su contestacion, pidiendo las causas pendientes de los cuatro representantes, á cuya elección habia interpuesto su VETO (1820). Buenos Aires: Imprenta de la Independencia. Recuperado de: https://archive.org/details/oficiodelahonora00buen, pp. 3-4.

Proceso original justificativo contra los reos acusados de Alta Traición en el Congreso y Directorio, mandados juzgar por el Articulo Septimo del Tratado de Paz firmado por este Gobierno con los Gefes de las Fuerzas Federales de Santa Fe y la Banda Oriental en veintitrés de febrero del corriente año de 1820 (1820).Buenos Aires: Imprenta de Alvarez. Biblioteca Nacional, Hemeroteca, Sala de Reservados $\mathrm{n}^{\circ}$ 12.033. Recuperado de: https://archive.org/stream/procesooriginalj00buen\#page/n5/mode/2up, pp. 3-4.

\section{Bibliografía}

Agüero, A. (2016). Ancient Constitution or paternal government? Extraordinary powers as legal response to political violence (Río de la Plata, 1810 -1860). En Max Planck Institute for European Legal History Research Paper Series (pp. 1-31). Frankfurt: Social Science Research Network (SSRN) eLibrary.

Barriera, D. y Tío Vallejo, G. (Coords.). (2012). Historia Política e Historia del Derecho: confluencias, divergencias y resistencias. PolHis, 10, 23-101. Recuperado de: http://archivo.polhis.com.ar/polhis10/

Botana, N. (2016). Repúblicas y Monarquías. La encrucijada de la independencia. Buenos Aires: Edhasa. 
Candioti, M. (2015). Ley, Justicia y revolución en Buenos Aires, 1810-1830. En Tesis del Ravignani. Buenos Aires: Instituto de Historia Argentina y Americana “Dr. Emilio Ravignani”, UBA, CONICET. Recuperado de: http://www.ravignanidigital.com.ar/tms/series/tesis ravig/ltr-004-tesiscandioti-2010.pdf

Candioti, M. y Tio Vallejo, G. (Coords.) (2012). Justicia y política entre el orden colonial y el orden constitucional en espacios hispanoamericanos. historiapolitica.com, Dossier 22. Recuperado de http://historiapolitica.com/dossiers/dossiersjusticiaypolitica/

Cansanello, C. (2003). De súbditos a ciudadanos. Ensayo sobre las libertades en los orígenes republicanos. Buenos Aires 1810-1852. Buenos Aires: Imago Mundi.

Chiaramonte, J. C. (1997). Ciudades, provincias, estados: Orígenes de la Nación Argentina (18001846). Buenos Aires: Ariel.

Chiaramonte, J. C. (1999). Ciudadanía, soberanía y representación en la génesis del Estado argentino (c. 1810-1852). En Sabato, H. (Coord.) Ciudadanía política y formación de las naciones. Perspectivas históricas de América Latina (pp. 94-116). México: FCE, COLMEX, FHA.

Chiaramonte, J.C. (2010). La antigua constitución luego de las independencias, 1808-1852. Desarrollo económico, 50(199), 331-361.

Di Meglio, G. (2008). República. En Goldman, N. (Ed.) Lenguaje y Revolución. Conceptos políticos clave en el Río de la Plata, 1780-1850 (pp. 145-158). Buenos Aires: Prometeo.

Gallo, K. (2016). Entre Viena y Tucumán. Las paradojas de la emancipación Argentina 1814-1820. Anuario del Instituto de Historia Argentina, 16(1), e004. Recuperado de http://www.anuarioiha.fahce.unlp.edu.ar/article/view/IHAv16n1a04

Goldman, N. y Di Meglio, G. (2008). Pueblo/Pueblos. En Lenguaje y revolución. Conceptos políticos clave en el Río de la Plata, 1780-1850 (pp. 131-143). Buenos Aires: Prometeo.

Goldman, N. y Wasserman, F. (2016). Un balance de la Historia Política en el proceso de independencia. Investigaciones y Ensayos, 62, 23-46.

Halperin Donghi, T. (2005). Revolución y guerra. Formación de una elite dirigente en la Argentina criolla. Buenos Aires: Siglo XXI Editores Argentina.

Halperin Donghi, T. (2010). De la revolución de independencia a la confederación rosista. Buenos Aires: Editorial Paidós.

Herrero, F. (2010) “Un gobierno federal”, “liberal y de principios”. La experiencia del gobierno de Manuel de Sarratea durante el crítico año de 1820. Andes, 21, 261-293. Recuperado de: http://www.redalyc.org/articulo.oa?id=12721040011

Ibáñez Frocham, M. (1938). La organización judicial argentina, La Plata: Impresori E Boletín.

Levene, R. (1962). Manual de Historia del Derecho Argentino. Buenos Aires: Editorial Kraft.

Lorente, M. y Portillo Valdés, J. M. (Dirs.) (2012). El momento gaditano. La Constitución en el orbe hispánico (1808-1826). Madrid: Cortes Generales. 
Manin, B. (2006). Los principios del gobierno representativo. Madrid: Alianza Editorial.

Mariluz Urquijo, J. M. (1953). Los juicios de residencia en el derecho patrio. Revista del Instituto del Historia del Derecho, 5, 108-122.

Méndez Calzada, L. (1960). La función judicial en las primeras épocas de la independencia. Buenos Aires: Editorial Losada.

Palti, E. (2007). El tiempo de la política. El siglo XIX reconsiderado. Buenos Aires: Siglo XXI.

Pérez, J. (1950) Historia de los primeros gobernadores de la provincia de Buenos Aires. El año XX desde el punto de vista político-social. La Plata: Archivo histórico de la provincia de Buenos Aires.

Polastrelli, I. (2013). Excluir y castigar a los opositores en la Revolución. Notas sobre el juicio de residencia dispuesto por la Asamblea del año XIII. PolHis, 12, 73-82. Recuperado de: http://archivo.polhis.com.ar/datos/Polhis12 POLASTRELLI.pdf

Polastrelli, I. (2017). La revolución fiscalizada. Los juicios de residencia en el Río de la Plata, 1810-1820. Nuevo Mundo Mundos Nuevos. Recuperado de: http://nuevomundo.revues.org/71280

Ravignani, E. (Ed.). (1937). Asambleas Constituyentes Argentinas. Buenos Aires: Instituto de Investigaciones Históricas de la Facultad de Filosofía y Letras, UBA.

Rosanvallon, P. (2007). La contrademocracia. La política en la era de la desconfianza. Buenos Aires: Manantial.

Segreti, C. (1994) La máscara de la monarquía: 1808-1819. Córdoba: Centro de Estudios Históricos.

Souto, N. y Wasserman, F. (2008). Nación. En Goldman, N. (Ed.). Lenguaje y Revolución. Conceptos políticos clave en el Río de la Plata, 1780-1850 (pp. 83-98). Buenos Aires: Prometeo, 2008.

Souto, N. (2016). La idea de unidad en tiempos del Congreso de 1816-1819. Anuario del Instituto de Historia Argentina, 16(1), e003. Recuperado de http://www.anuarioiha.fahce.unlp.edu.ar/article/view/IHAv16n1a03

Tau Anzoátegui, V. (1961). Facultades extraordinarias y la suma del poder público en el Derecho Provincial Argentino (1820-1853). Revista del Instituto de Historia del Derecho, 12, 66-105.

Ternavasio, M. (2007). Gobernar la revolución Gobernar la revolución. Poderes en disputa en el Río de la Plata, 1810-1816. Buenos Aires: Siglo XXI Editores.

Ternavasio, M. (2015). Candidata a la Corona. La infanta Carlota Joaquina en el laberinto de las revoluciones hispanoamericanas. Buenos Aires: Siglo XXI Editores.

Verdo, G. (2016). Las independencias olvidadas: La Nación y las provincias en la época de la declaración. En Entin, G. (Ed.). Crear la independencia. Historia de un problema argentino (pp. 73-94). Buenos Aires: Capital Intelectual. 